\title{
Synergistic Effects of Lactic Acid and Sodium Dodecyl Sulfate to Decontaminate Escherichia coli 0157:H7 on Cattle Hide Sections
}

\author{
Mohamed G. Elramady, Sharif S. Aly, ${ }^{1,2}$ Paul V. Rossitto, Jennifer A. Crook, and James S. Cullor ${ }^{1,2}$
}

\begin{abstract}
The objective of this study was to investigate the antibacterial properties of chitosan acetate (CA), sodium dodecyl sulfate (SDS), lactic acid (LA) and their synergism when combined against a nontoxigenic strain of Escherichia coli O157:H7. Treatments that significantly reduced the concentration of E. coli O157:H7 in vitro by more than two logs were further investigated using a cattle hide decontamination model. In vitro treatments included CA ( $1 \%$ chitosan in $1 \%$ acetic acid vol/vol), SDS ( $1 \% \mathrm{vol} / \mathrm{vol})$, SDS ( $2 \% \mathrm{vol} / \mathrm{vol})$, LA ( $1 \% \mathrm{vol} / \mathrm{vol})$, CA-SDS combination ( $1 \%$ chitosan in $1 \%$ acetic acid vol/vol mixed with $1 \%$ SDS vol/vol), and LA-SDS combination in two different concentrations (1\% LA mixed with $1 \%$ SDS vol/vol, and $1 \%$ LA mixed with $2 \%$ SDS vol/vol). Butterfield's Phosphate Buffer water was used as a control. The antibacterial effect of $1 \%$ CA solution alone and in combination with 1\% SDS in vitro resulted in a 1.8 and 1.7 log colony-forming units $(\mathrm{CFU}) / \mathrm{mL}$ reduction, respectively $(p<0.05)$. Only $1 \% \mathrm{LA}, 1 \% \mathrm{SDS}, 2 \%$ SDS and their combinations resulted in a $>2 \log$ reduction in E. coli O157:H7. On hide sections, both 1\% LA-1\% SDS and 1\% LA-2\% SDS combinations significantly $(p<0.05)$ reduced E. coli O157:H7 concentration by 4.6 and $4.7 \mathrm{log} \mathrm{CFU} / \mathrm{cm}^{2}$ greater than the control, respectively. There was no significant difference in the antibacterial effect of $1 \%$ LA compared to the control, $2 \%$ SDS compared to the control, or 1\% LA compared to $2 \%$ SDS. Hence, the antibacterial efficacy of 1\% LA against E. coli O157:H7 on hide sections was significantly enhanced when combined with 1\% SDS. Results of this study support the use of low concentration LA-SDS combination as a hide wash to reduce the risk of E. coli O157:H7 contamination.
\end{abstract}

\section{Introduction}

E SCHERICHIA COLI O157:H7 is often incriminated in foodborne outbreaks associated with beef consumption (Vogt and Dippold, 2005; Currie et al., 2007). Ruminants are reservoirs of E. coli O157:H7, and carcass contamination may occur through direct contact or aerosols during removal of hides contaminated with feces containing E. coli O157:H7 (Byelashov and Sofos, 2009).

Antibacterial properties of natural compounds such as chitosan acetate (CA) have been studied (Friedman and Juneja, 2010). The effect of chitosan on E. coli O157:H7 on hides has not been studied. Similarly, the food additive sodium dodecyl sulfate (SDS) enhances the antibacterial properties of organic acids (Zhao et al., 2009). The objective of this study was to investigate the antibacterial properties of CA, SDS, and lactic acid (LA) against E. coli O157:H7 in vitro and on inoculated cow-hide sections.

\section{Materials and Methods \\ Inoculum preparation}

A frozen stock culture of E. coli O157:H7 (ATCC 43888) stored at $-80^{\circ} \mathrm{C}$ was transferred onto sheep blood agar and incubated for $18 \mathrm{~h}$ at $37^{\circ} \mathrm{C}$ three consecutive times. The culture was stored at $4^{\circ} \mathrm{C}$ and subcultured twice on sheep blood agar before each experiment. After the second pass, two colonies were transferred to $25 \mathrm{~mL}$ of tryptic soy broth (TSB) and incubated for $18 \mathrm{~h}$ at $37^{\circ} \mathrm{C}$. Concentration of the pure culture was then adjusted to $10^{8} \mathrm{CFU} / \mathrm{mL}$ by dilution.

\section{Reagent preparation}

Eight treatments were evaluated in vitro: (1) $1 \%$ CA (chitosan in $1 \%$ acetic acid vol/vol, $\mathrm{pH} 3.7) ;(2)$ combination of $1 \%$ CA and $1 \%$ SDS vol/vol (pH 4.2); (3) 1\% SDS (pH 3.2); (4) $2 \%$ SDS (pH 3.2); (5) 1\% lactic acid (pH 2.7); (6) combination of $1 \%$

\footnotetext{
${ }^{1}$ Veterinary Medicine Teaching and Research Center, School of Veterinary Medicine, University of California, Davis, Tulare, California.

${ }^{2}$ Department of Population Health and Reproduction, School of Veterinary Medicine, University of California, Davis, California.
} 
Table 1. Post-treatment Concentration of Escherichia coli O157:H7 (ATCC 43888) in Vitro and on Experimentally Inoculated Cow Hide Sections

\begin{tabular}{|c|c|c|c|c|c|}
\hline \multirow[b]{2}{*}{ Treatment type } & \multicolumn{3}{|c|}{ In vitro experiment } & \multicolumn{2}{|c|}{ Hide decontamination model } \\
\hline & $p H$ & $\begin{array}{c}\text { Mean }^{\text {a }} \text { survival } \\
(\log C F U / m L) \\
\text { (Standard deviation) }\end{array}$ & $\begin{array}{c}\text { Mean killed } \\
(\log C F U / m L)\end{array}$ & $\begin{array}{c}\text { Mean }^{\text {a }} \text { survival } \\
\left(\log \text { CFU/ } \mathrm{cm}^{2}\right) \\
\text { (Standard deviation) }\end{array}$ & $\begin{array}{c}\text { Mean killed } \\
\left(\log \mathrm{CFU} / \mathrm{cm}^{2}\right)\end{array}$ \\
\hline Control (Butterfield's Phosphate Buffer water) & 7.2 & $8.0 \mathrm{~A}(0.6)$ & 0.0 & $6.0 \mathrm{~A}(0.2)$ & 0.0 \\
\hline Chitosan acetate in acetic acid (1\%/1\%) & 3.7 & $6.2 \mathrm{~B}(0.5)$ & 1.8 & & \\
\hline Chitosan acetate in acetic acid $(1 \% / 1 \%)-1 \%$ SDS & 4.2 & $6.3 \mathrm{~B}(0.5)$ & 1.7 & & \\
\hline $1 \%$ Lactic acid & 2.7 & $4.4 \mathrm{C}(0.4)$ & 3.6 & $5.7 \mathrm{~A}(0.8)$ & 0.3 \\
\hline $1 \%$ SDS & 3.2 & $2.1 \mathrm{D}(0.1)$ & 5.9 & & \\
\hline $2 \%$ SDS & 3.2 & $<2.0^{\mathrm{b}} \mathrm{D}$ & $>6.0$ & $5.6 \mathrm{~A}(0.3)$ & 0.4 \\
\hline $1 \%$ Lactic acid-1\% SDS & 2.7 & $<2.0^{\mathrm{b}} \mathrm{D}$ & $>6.0$ & $1.4 \mathrm{~B}(0.9)$ & 4.6 \\
\hline $1 \%$ Lactic acid- $2 \%$ SDS & 2.7 & $<2.0^{\mathrm{b}} \mathrm{D}$ & $>6.0$ & $1.3 \mathrm{~B}(0.7)$ & 4.7 \\
\hline
\end{tabular}

${ }^{\mathrm{a}}$ Means with different letters are significantly different $(p<0.05)$.

${ }^{\mathrm{b}}$ Concentrations were calculated by using the method's detection limit.

CFU, colony-forming units; SDS, sodium dodecyl sulfate.

LA and 1\% SDS vol/vol (pH 2.7); (7) combination of 1\% LA and $2 \%$ SDS vol/vol ( $\mathrm{pH} 2.7$ ); (8) Butterfield's Phosphate Buffer water (BB, pH 7.2) as a negative control. Treatments that significantly reduced the concentration of E. coli 0157:H7 in vitro by more than 2 logs were further investigated using a cattle hide decontamination model. Only the latter five treatments were used in the hide decontamination model. Morpholinepropanesulfonic acid (MOPS) was used for neutralization of low $\mathrm{pH}$ after chemical treatments (Park and Chen, 2011).

\section{In vitro experiment}

Each treatment was conducted in four independent replicates at room temperature. For each replicate, $9 \mathrm{~mL}$ of the solution was mixed with $1 \mathrm{~mL}$ of the E. coli O157:H7 inoculum. Samples were taken after $5 \mathrm{~min}$ and diluted (1:10) in $0.05 \mathrm{M}$ MOPS ( $\mathrm{pH}$ 7.4). Neutralized samples were serially diluted in BB and volumes of $0.1 \mathrm{~mL}$ were spread plated, in duplicate, onto ct-SMAC agar (Sorbitol MacConkey agar with cefixime and tellurite) and incubated at $37^{\circ} \mathrm{C}$ for $24 \mathrm{~h}$. Absence of colony growth on plates of the first dilution $\left(10^{-1}\right)$ indicated that the bacterial concentration was below the detection limit $(2.0 \log \mathrm{CFU} / \mathrm{mL})$.

\section{Hide Decontamination Model}

Three cow hides were harvested at a slaughter plant, and $10-\mathrm{cm} \times 10-\mathrm{cm}$ sections were cut from the ventral midline. Hide sections were positioned hair sides facing each other (Antic et al., 2010), placed in sterile bags and stored at $-20^{\circ} \mathrm{C}$ before being thawed at room temperature $2 \mathrm{~h}$ prior to each experiment. Inoculations and treatments were performed in four independent replicates in a biosafety cabinet. Hide sections were inoculated with $1 \mathrm{~mL}$ of adjusted culture at $10^{8}$ $\mathrm{CFU} / \mathrm{mL}$ using a pipette over the midline of a $5-\mathrm{cm} \times 10-\mathrm{cm}$ area. The inoculum was then distributed uniformly by five vertical followed by five horizontal strokes (Carlson et al., 2008) using a sterile disposable L-shaped rod and left to dry for $5 \mathrm{~min}$. Each inoculated area was uniformly treated by 12 hand sprays that delivered $10 \mathrm{~g}$ of dispensed volume. A $5 \mathrm{~min}$ reaction time was allowed prior to sampling using a sterile dry sponge stick by applying five horizontal followed by five vertical motions. The sponge was then hand-massaged for $1 \mathrm{~min}$ in a sterile bag containing $25 \mathrm{~mL}$ of $0.05 \mathrm{M}$ MOPS and the eluted contents enumerated as described in the in vitro experiment. Absence of growth on plates of the first dilution $\left(10^{-1}\right)$ indicated that the bacterial concentration was below the detection limit $\left(0.7 \log \mathrm{CFU} / \mathrm{cm}^{2}\right)$.

\section{Statistical analysis}

The surviving $\log \mathrm{CFU} / \mathrm{mL}$ or $\log \mathrm{CFU} / \mathrm{cm}^{2}$ of hide were analyzed using a one-way analysis of variance with multiple comparisons at 5\% level of significance. A treatment's disinfecting effect was estimated as the difference in E. coli O157:H7 concentration between the treatment and control (BB).

\section{Results and Discussion}

Table 1 summarizes the in vitro and hide decontamination experiments. All seven in vitro treatments significantly reduced the survival of E. coli O157:H7 $(p<0.05)$. Treatments containing CA resulted in $<2 \log \mathrm{CFU} / \mathrm{mL}$ reduction hence were not included in the hide experiment. Treatments $1 \%$ SDS, $2 \%$ SDS, or either in combination with $1 \%$ LA reduced surviving E. coli O157:H7 concentrations by $>2 \log \mathrm{CFU} / \mathrm{mL}$ but did not differ significantly among each other $(p>0.05)$.

On hide sections, only the combination of LA and SDS significantly reduced the concentration of E. coli O157:H7 by $4.6 \operatorname{logs}$ compared to the control. The lack of antibacterial effect of either chemical independently on hides may be due to the complex hide surface and normal microbiota (2.9-3.5 log $\mathrm{CFU} / \mathrm{cm}^{2}$, data not shown). Increasing the concentration of SDS to $2 \%$ in combination with $1 \%$ LA did not result in additional antibacterial effect. As a surfactant, SDS denatures proteins and destroys bacterial cell membranes at a low $\mathrm{pH}$ (Zhao et al., 2009). Synergism between LA and SDS may be explained by the ability of LA to increase the permeability of the bacterial cell membrane by releasing lipopolysaccharides, which may render bacteria more sensitive to SDS (Alakomi et al., 2000). Although a $\mathrm{pH}<3$ is bactericidal against Gramnegative bacteria (Tanner et al., 1992), the minimal antibacterial effect on hide sections by $1 \% \mathrm{LA}$ at $\mathrm{pH} 2.7$ and $2 \%$ SDS at $\mathrm{pH} 3.2$ indicates that the $\mathrm{pH}$ alone was not effective in this 
study. In conclusion, SDS enhanced the antibacterial effect of 1\% LA against E. coli O157:H7 on hide sections. The combination may be a safe hide wash, given its low concentration.

\section{Acknowledgments}

This project was partially supported by AFRI Grant No. 2012-68003-30155 from the USDA NIFA, Prevention, Detection, and Control of Shiga Toxin-Producing Escherichia coli (STEC) from Pre-Harvest Through Consumption of Beef Products Program-A4101, Dairy Food Safety Laboratory and Dairy Epidemiology Laboratory of the Veterinary Medicine Teaching and Research Center, and the Master in Preventive Veterinary Medicine Research Project Award by Musser Scholarship, School of Veterinary Medicine, University of California, Davis. The authors would like to thank Mr. J. Parko for technical assistance.

\section{Disclosure Statement}

No competing financial interests exist.

\section{References}

Alakomi HL, Skytta E, Saarela M, Mattila-Sandholm T, LatvaKala K, Helander IM. Lactic acid permeabilizes gram-negative bacteria by disrupting the outer membrane. Appl Environ Microbiol 2000;66:2001-2005.

Antic D, Blagojevic B, Ducic M, Mitrovic R, Nastasijevic I, Buncic S. Treatment of cattle hides with Shellac-in-ethanol solution to reduce bacterial transferability: A preliminary study. Meat Science 2010;85:77-81.

Byelashov OA, Sofos JN. Strategies for on-line decontamination of carcasses. In: Safety of Meat and Processed Meat. Toldrá F (ed.). New York: Springer Science+ Business Media, 2009, pp. 149-182.
Carlson BA, Ruby J, Smith GC, Sofos JN, Bellinger GR, WarrenSerna W, Centrella B, Bowling RA, Belk KE. Comparison of antimicrobial efficacy of multiple beef hide decontamination strategies to reduce levels of Escherichia coli O157:H7 and Salmonella. J Food Prot 2008;71:2223-2227.

Currie A, MacDonald J, Ellis A, Siushansian J, Chui L, Charlebois M, Peermohamed M, Everett D, Fehr M, Ng LK. Outbreak of Escherichia coli 0157:H7 infections associated with consumption of beef donair. J Food Prot 2007;70:1483-1488.

Friedman M, Juneja VK. Review of antimicrobial and antioxidative activities of chitosans in food. J Food Prot 2010; 73:1737-1761.

Park YJ, Chen J. Mitigating the antimicrobial activities of selected organic acids and commercial sanitizers with various neutralizing agents. J Food Prot 2011;74:820-825.

Tanner RS, James SA. Rapid bactericidal effect of low $\mathrm{pH}$ against Pseudomonas aeruginosa. J Indust Microbiol Biotechnol 1992;10: 229-232.

Vogt RL, Dippold L. Escherichia coli O157:H7 outbreak associated with consumption of ground beef, June-July 2002. Public Health Rep 2005;120:174-178.

Zhao T, Zhao P, Doyle MP. Inactivation of Salmonella and Escherichia coli O157:H7 on lettuce and poultry skin by combinations of levulinic acid and sodium dodecyl sulfate. J Food Prot 2009;72:928-936.

Address correspondence to: Sharif S. Aly, BVSc, MPVM, PhD

Veterinary Medicine Teaching and Research Center School of Veterinary Medicine University of California, Davis 18830 Road 112 Tulare, CA 93274

E-mail: saly@ucdavis.edu 